\title{
Investigating the impact of climate change on New York City's primary water supply
}

\author{
Adão H. Matonse • Donald C. Pierson • Allan Frei • \\ Mark S. Zion • Aavudai Anandhi • \\ Elliot Schneiderman • Ben Wright
}

Received: 7 October 2010 / Accepted: 4 June 2012 / Published online: 28 June 2012

(C) The Author(s) 2012. This article is published with open access at Springerlink.com

\begin{abstract}
Future climate scenarios projected by three different General Circulation Models and a delta-change methodology are used as input to the Generalized Watershed Loading Functions Variable Source Area (GWLF-VSA) watershed model to simulate future inflows to reservoirs that are part of the New York City water supply system (NYCWSS). These inflows are in turn used as part of the NYC OASIS model designed to simulate operations for the NYCWSS. In this study future demands and operation rules are assumed stationary and future climate variability is based on historical data to which change factors were applied in order to develop the future scenarios. Our results for the West of Hudson portion of the NYCWSS suggest that future climate change will impact regional hydrology on a seasonal basis. The combined effect of projected increases in winter air temperatures, increased winter rain, and earlier snowmelt results in more runoff occurring during winter and slightly less runoff in early spring, increased spring and summer evapotranspiration, and reduction in number of days the system is under drought conditions. At subsystem level reservoir storages, water releases and spills appear to be higher and less variable during the winter months and are slightly reduced during summer. Under the projected future climate and assumptions in this study the NYC reservoir system continues to show high resilience, high annual reliability and relatively low vulnerability.
\end{abstract}

\section{Introduction}

Projected twenty first century changes in air temperature and precipitation patterns due to climate change may alter the availability of water leading to new challenges for water supply

\author{
A. H. Matonse $(\bowtie) \cdot$ A. Frei \\ City University of New York (CUNY) Institute for Sustainable Cities (CISC), New York City, NY 10065, USA \\ e-mail: amatonse@hunter.cuny.edu
}

D. C. Pierson • M. S. Zion • E. Schneiderman

New York City Department of Environmental Protection, Kingston, NY 12401, USA

\author{
A. Anandhi \\ Department of Agronomy, Kansas State University, Manhattan, KS 66506, USA
}

B. Wright

Hazen and Sawyer, P.C., Baltimore, MD 21202, USA 
planning and management in many regions throughout the world (Bates et al. 2008; Hunt and Watkiss 2011; Vicuna and Dracup 2007; Gleckler et al. 2008) including the New York City (Rosenzweig and Solecki 2001). For mountainous regions of the northeastern U.S. these changes can reduce annual snowpack accumulation, accelerate snowmelt processes and increase water losses due to evapotranspiration (ET) which may lead to more winter flooding and reduced summer flows (Brekke et al. 2009; Milly et al. 2005; Seager et al. 2007; Burns et al. 2007; Blake et al. 2000; Vicuna and Dracup 2007; Frei et al. 2002; Matonse et al. 2011). The potential impact of climate change on the ability to meet future demands for high quality drinking water, and satisfy other competing goals for surface water supplies (Bates et al. 2008; Brekke et al. 2009), is an issue of importance in many regions in U.S. and around the world and of primary concern to New York City (NYC) (NYCDEP 2008). A thorough investigation of climate change impacts on the NYC water supply system (NYCWSS) should include, in addition to climatic variations, the operational constraints of the system and potential responses through adaptive management in order to meet demands and other day-to-day operational goals (NYCDEP 2008).

The NYCWSS is a system of nineteen reservoirs and connecting aqueducts that deliver more than $3.8 \times 10^{6}$ cubic meters of drinking water per day to approximately nine million people in NYC and four upstate counties (Matonse et al. 2011). The Catskill and Delaware watersheds that constitute the West of Hudson (WOH) portion of the NYCWSS cover an area of approximately 4100 square kilometers in the Catskill Mountain region and contribute more than $90 \%$ of all water supplied to NYC. As illustrated in Fig. 1 the Delaware

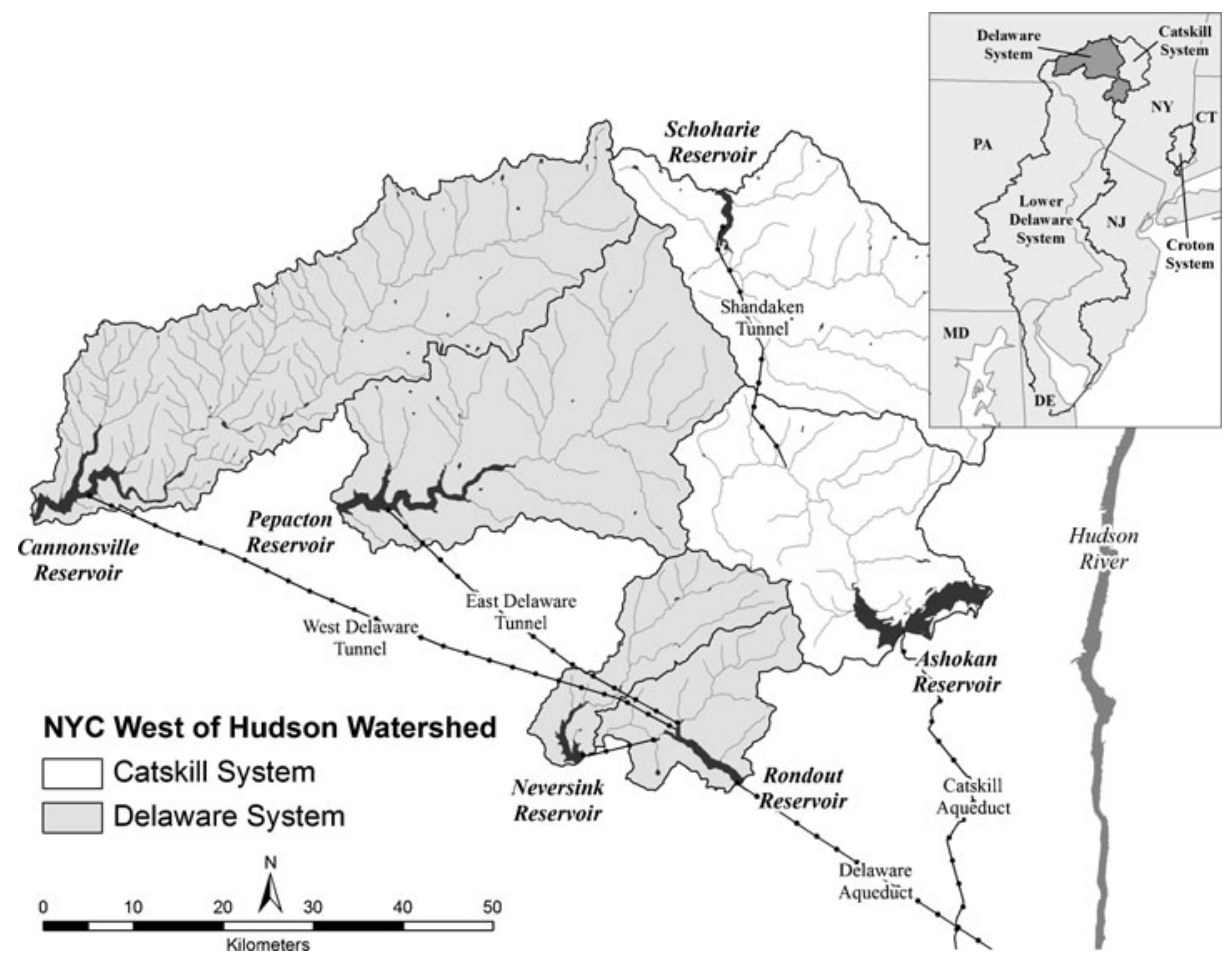

Fig. 1 NYC WOH Catskill and Delaware watersheds and aqueducts schematic. The NYC Croton and the Lower Delaware (LD) systems are represented in the location map on the top right corner. Regulatory rules requires NYC WOH system to deliver water to LD that serves New Jersey and Pensylvania (adapted from Matonse et al. 2011) 
subsystem of the WOH water supply has a 2621 square kilometer drainage area that includes the Pepacton, Cannonsville, Rondout and Neversink reservoirs. The Ashokan and Schoharie reservoirs form the Catskill subsystem, which covers the remaining 1479 square kilometers. Table 1 summarizes major characteristics of the Delaware and Catskill subsystems.

The Catskill Mountain region is part of the Allegheny Plateau consisting mainly of sedimentary bedrock that rises approximately $1100 \mathrm{~m}$ in elevation from the Hudson River, its eastern boundary (Burns et al. 2007). The region is mostly rural and forested with some dairy farms in low-land areas, particularly in the western part of the mountains. About $70 \%$ (2850 square $\mathrm{km}$ ) of the WOH area is part of the New York State Catskill Forest Preserve. The climate of this region is humid continental with relatively cold winters and cool summers. The temperature is variable among locations in the region and is highly impacted by elevation. Annual average temperatures range between $5.2^{\circ} \mathrm{C}$ at higher elevations (Slide Mountain, $807 \mathrm{~m}$ elevation) and $7.5{ }^{\circ} \mathrm{C}$ at valley locations (Walton, $450 \mathrm{~m}$ elevation). Regional hydrology in NYC WOH watersheds is strongly influenced by snowpack and snow melt particularly during March and April (Matonse et al. 2011).

Past studies addressing climate change impacts on the NYC water supply have projected changes in climatology and hydrology and found evidence to suggest that some of the projected changes are underway. Burns et al. (2007) applied a non-parametric Mann-Kendall test to study trends in air temperature, precipitation, streamflow and ET for the Catskill Mountain region during the period of 1952-2005. Over the course of their study they found a $0.6{ }^{\circ} \mathrm{C}$ increase in yearly air temperature with higher increases in daily minimum temperature during May through September and daily maximum temperature during February through April. Precipitation was observed to increase by $136 \mathrm{~mm}$ and ET by $19 \mathrm{~mm}$ per 50 years. Peak snowmelt showed a shift from early April to late March with a reduction in snowpack consistent with patterns in streamflow and monthly air temperature. Frei et al. (2002) arrived at similar results when applying a version of the Thornthwaite water-balance model to study inter-annual variations and sensitivity to climate change for the Cannonsville basin (Delaware subsystem). In addition, the results from Frei et al. (2002) indicated a change in mean annual streamflow of approximately $6 \%$ per degree $\mathrm{C}$ change in average annual temperature and a 1.5-2\% change of annual streamflow for each percent change in annual precipitation. These changes in hydrology indicate that as a result of climate change more water will become streamflow during winter potentially filling the reservoirs earlier in the spring (Matonse et al. 2011), but also increasing the potential for regional flooding (Burns et al. 2007). These results also suggest that for the NYC WOH watersheds projected increases in precipitation generally surpass the effects of increased water loss due to higher ET rates associated with higher temperatures. Conversely as suggested by Blake et al. (2000), if increases in precipitation are not as large as expected,

Table 1 Major characteristics of the WOH watersheds. Historical dependable yield is the maximum withdrawal that can be continuously obtained during a period of years which represent the probable driest period (Joint Editorial Board 1969; Mays and Tung 1992)

\begin{tabular}{llllll}
\hline Subsystem & $\begin{array}{l}\text { Storage capacity } \\
\left(10^{6} \text { cu.m) }\right.\end{array}$ & $\begin{array}{l}\text { Historical } \\
\text { dependable } \\
\text { yield }(\mathrm{cms})^{*}\end{array}$ & $\begin{array}{l}\text { Drainage } \\
\text { area } \\
(\mathrm{sq} . \mathrm{Km})\end{array}$ & $\begin{array}{l}\text { Annual } \\
\text { average } \\
\text { flow }(\mathrm{cms})\end{array}$ & $\begin{array}{l}\text { Coefficient } \\
\text { of variation } \\
\text { (annual flow) }\end{array}$ \\
\hline $\begin{array}{l}\text { Delaware } \\
\text { Catskill }\end{array}$ & 1212 & 25.4 & 2621 & 51.7 & 0.27 \\
\end{tabular}

* Source: New York City Department of Environmental Protection (NYCDEP) (2006) NYC water supply system Reference guide, Valhalla, NY 
the resulting reduction in water availability from increased winter spill and summer ET could lead to a greater risk of drought and increased drought severity.

The management of large systems such as the NYC water supply system is complex as it depends on watershed hydroclimatologic characteristics, reservoir capacities, reservoir operating rules, and system demands (Vogel et al. 1995). Operational complexity is a consequence of the large number of interconnected reservoirs and a decision-making process that includes meeting oft-times competing goals to satisfy demands, balance storage in different parts of the system so as to maximize water availability and minimize spills, meet regulatory flow requirements, and maintain water quality standards imposed on the system (NYCDEP 2011). One important aspect in this process is the management of extreme events to mitigate peak flows and drought (Matonse et al. 2011; Yin et al. 2010; Chang and Chang 2001) through the use of control structures and system operations in order to maintain reliability.

A variety of variables or indicators can be used to describe the operational state of the system. These include measures of inflow, reservoir storage and probability of future refill, releases, spills and demands on a daily, weekly, monthly and yearly basis. Some indicators describe the state of the system or its components (e.g. reservoir, subsystem, or other element) at a given point in time and are therefore very important for managing operations on a short-term basis. Other indicators, such as safe yield (NYCDEP 2008; Mayer 1993), system reliability and resilience (Vogel et al. 1995; Vogel and Bolognese 1995; Vogel 1987), storage vulnerability, surface and ground water stress, coefficient of variation of annual inflow (Lane et al. 1999), and standardized net inflow (Vogel et al. 1999) can be used to evaluate the overall performance of the system on a seasonal and/or long-term basis. Most of these indicators have been used in the past in order to: (i) summarize the effectiveness of regional water supply systems to meet demands (Lane et al. 1999), (ii) compare the relative performance of proposed improvements to water supply infrastructure, (iii) evaluate the effectiveness of reservoir operation policies (Yin et al. 2010), (iv) study the impact of new regulatory procedures, and most recently (v) assess the impact of climate change on existing reservoir systems (Lane et al. 1999; Vogel et al. 1999).

Ongoing nationwide infrastructure and system reliability assessments in the United States highlight the importance of system indicators (Harberg 1997; Vogel et al. 1999). Globally, a growing importance is given to local and regional assessment of water systems in balancing water supply and ecological needs, or socio-economic and environmental objectives (Vogel et al. 2007; Lane et al. 1999; Rogers 1999; Gao et al. 2009; Richter et al. 1996) or characterizing the effects of regulation on flow regimes (Black et al. 2005). Vogel et al. (1995) studied the storage-reliability-resilience-yield relationship for four different water supply systems in the northeastern United States, including the NYCWSS. The objective was to integrate the effects of hydroclimatologic characteristics, reservoir system storage capacity, operating rules, and system yield in a systematic manner to answer questions about which water supply systems are most vulnerable to major water supply failure (i.e., inability to satisfy demands) in the region, and what characteristics make one water supply system more vulnerable or more resilient to drought than others. For this study we combined indicators that provide important information for daily operations with those that help evaluate overall reservoir system performance.

\section{The OASIS model and the NYCWSS modeling framework}

This evaluation relied on two primary modeling tools: a rainfall-runoff model serially coupled with a reservoir system model. The Operational Analysis and Simulation of 
Integrated Systems (OASIS) is a reservoir system model, which simulates water supply system operations, accounting for both "human control and physical constraints on the system" (HydroLogics Inc. 2007). OASIS is a generalized program that has been customized to the NYCWSS (NYCDEP 2011) by specifying a system framework and rules that are specific to NYCWSS. Each of the reservoirs and conveyances of the system are represented as nodes and arcs that store and transfer water on a daily basis. System properties (e.g., reservoir storage capacities, flow capacities, elevations of control structures, etc.) represent the physical properties and constraints of the system components. A complex set of rules codify the day-to-day decision making process of actual operation of the system by weighing actions in relation to competing goals and constraints, while a linear programming (LP) routine determines the optimal set of actions on each day. The rules embody both empirical knowledge accumulated during years of operating the system and the current regulations and water quality requirements for the system. Examples of operating objectives represented in the OASIS model include:

- Meeting regulatory release requirements for NYC reservoirs;

- Balancing diversions from the Delaware, Catskill and Croton subsystems; and

- Meeting demands from both NYC and outside communities (OC).

The operating rules expressed in the OASIS model provide a robust simulation of NYC reservoir system operations under current operating protocols.

A modeling framework for the NYC water supply system includes OASIS linked to other models (Fig. 2). The NYC OASIS model has been linked to a calibrated set of CE-Qual-W2 (Cole and Wells 2002) reservoir models for modeling in-reservoir water quality processes. However, for this analysis, a simplified method based on empirical relationships between

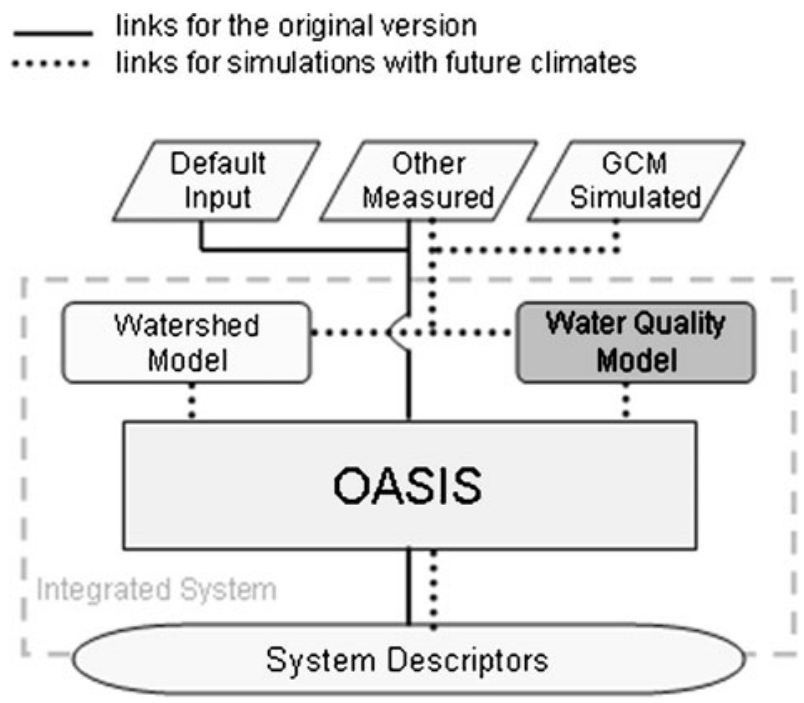

Fig. 2 OASIS modeling framework. The black lines show the model linkages using the historical flow inputs. The doted lines show the flow input linkages using the GWLF-VSA modeled inflows for current and future climate change scenarios. The Water Quality model box is shown in dark gray color to indicate that water quality inputs to OASIS can be obtained from either a fully coupled reservoir water quality model, or from simplified indices of water quality based on empirical relationships using reservoir stage and flow 
turbidity and the storage/flow properties of the system was incorporated into OASIS. This method represents a faster alternative compared to running the linked OASIS- W2 model.

In its original form the NYC OASIS model was driven by historical stream flow inputs (Fig. 2 with links in black). As part of this study, the model was configured to use input derived from climate change scenario simulations. Future streamflow projections were obtained from simulations using the Generalized Watershed Loading Functions-Variable Source Area (GWLF-VSA) model (Schneiderman et al. 2007; Schneiderman et al. 2002; Haith and Shoemaker 1987). GWLF-VSA is a lumped-parameter continuous simulation model that simulates daily streamflow, nutrients, and sediment loads on a watershed scale. GWLF-VSA forcing inputs include daily air temperature, precipitation, incoming solar radiation, and daily average relative humidity. Both, the original GWLF (Haith and Shoemaker 1987) and GWLF-VSA treat the watershed as a system of different land areas (Hydrologic Response Units or HRUs) that produce surface runoff, and a single groundwater reservoir that supplies baseflow. GWLF-VSA differs from the original GWLF (Haith and Shoemaker, 1987) in that it simulates saturation-excess runoff on variable source areas, which is considered the primary runoff generation mechanism in WOH watersheds (Walter et al. 2003). To do so, GWLF-VSA simulates runoff volumes using the SCS Curve Number Method, as in the original GWLF model, but spatially-distributes the runoff response according to a soil wetness index, based on the TOPMODEL soils-topographic index (Schneiderman et al. 2007; Beven and Kirkby 1979). Potential evapotranspiration in GWLF-VSA is calculated using the Priestley-Taylor method (Priestley and Taylor 1972; Neitsch et al. 2005) with crop parameters varying between growing and dormant seasons. For this study GWLF-VSA is run over the entire reservoir basin area. As this area includes the reservoir surface itself, the model treats precipitation over the water surface as a direct inflow to the reservoir after subtracting potential evaporation.

Future scenarios of precipitation and air temperature derived from different GCM models using a delta-change methodology (Hay et al. 2000; Anandhi et al. 2011) were input into GWLF-VSA for all WOH reservoir watersheds (Fig. 2 with dotted links) to simulate inflows to the reservoir system. The complete integrated modeling framework including GWLFVSA and OASIS accurately simulate the state of the system over time and provide data to evaluate the performance of the system under projected changes in climate.

\section{Methods}

In the following sub-sections we describe briefly each of the indicators used in this study to evaluate possible effects of climate change on the NYC water supply. These indicators were selected based on their importance (i) for the NYC water supply operation and (ii) for assessing system performance and subsequent comparison with other systems at a regional level.

\subsection{Reservoirs storage, inflow, release, spill, and diversion}

Comparing patterns of storage, inflow, release and spill helps describes how the system functions. We compare indicators for the baseline and future projections simulated using different GCM climate scenarios. Inflows are related to hydro-climatic conditions, while the relationship between inflow, storage, release, and spill are governed by the rules within OASIS. Releases (i.e., controlled outflows from the reservoirs outlets) in the Delaware subsystem, for example, are governed by minimum downstream flow objectives and, to a 
lesser extent, peak flow mitigation and habitat protection. Delaware subsystem reservoirs are typically drawn down from November through March to create storage void equal to half the equivalent water volume in the snowpack and during this time diversions from the Catskill subsystem may be minimized. The Catskill subsystem includes rules to regulate water diversions from Schoharie reservoir through the Shandaken Tunnel to Esopus Creek. These rules account for allowable flow rates, temperature and turbidity limits for the tunnel discharges. Diversions of water from and between reservoirs are based on individual reservoir storage volumes, drought conditions, water quality, demands and local downstream requirements.

\subsection{Drought occurrence}

Drought occurrence is an indicator that is important for operations because it leads to temporary changes in the criteria for moving water from reservoirs and acts to trigger demand reductions. There are three drought levels in the NYCWSS: Watch, Warning, and Emergency. The classification and call for a particular drought level is executed by comparing the total storage of each subsystem with average yearly storage patterns associated with each drought level and each subsystem (Catskill and Delaware). The combination of the drought conditions in Delaware and Catskill subsystems determines the drought status for the entire NYCWSS.

\subsection{Standardized net inflow and reservoir system resilience}

The standardized net inflow $(m)$ (Perrens and Howell 1972; Vogel et al. 1999) is a unitless index that indicates whether a reservoir system is likely to have within-year or over-year variations in storage. This indicator can be calculated as:

$$
m=\frac{(1-\alpha) \mu}{\sigma}=\frac{(1-\alpha)}{C_{v}}
$$

where $\mu$ is the mean annual inflow, $\alpha$ is the average annual system demand or yield as a fraction $\mu, \sigma$ is the standard deviation of the annual inflows, and $C_{\nu}=\sigma / \mu$ is the coefficient of variation of the annual inflows. Systems with higher values of $m(m>1)$ are more likely to exhibit a within-year behavior whereas systems with $0 \leq m \leq 1$ are normally dominated by over-year behavior with long multiyear drawdown periods (Vogel and Stedinger 1987; Vogel et al. 1999). Within-year systems are characterized by reservoirs that typically refill at the end of each year. These systems often exhibit a relatively high resilience index (see below, and Vogel and Bolognese 1995) but they appear to be more sensitive to seasonal, monthly and daily variations in demands and inflows to the system. Past studies (Vogel and Bolognese 1995; Vogel et al. 1999) have revealed that under the present conditions the NYC water supply system exhibits within-year behavior.

Hashimoto et al. (1982) define a resilience index $(r)$ as a measure of the likelihood a particular system will recover after a failure has occurred, where failure or shortage is defined as inability of the reservoir system to supply its yield in a given year (Vogel et al. 1999). The resilience index for systems fed by lag-one autoregressive normally distributed inflows, as is the case in the northeastern United States (Vogel et al. 1995), can be estimated as

$$
r=\Phi\left[\frac{m-\frac{\rho(2 \pi)^{-1 / 2}}{\Phi(-m) \exp \left(m^{2} / 2\right)}}{\sqrt{1-\rho^{2}}}\right]
$$


where $\rho$ is the lag-one serial correlation coefficient of the inflows (equal to zero for independent inflows), $\Phi$ denotes the cumulative probability distribution operator for the standardized normal random variable, and $m$ is the standardized net inflow as defined above. Using goodness-of-fit tests on 166 watersheds in the northeastern United States Vogel et al. (1995) found that timeseries of annual streamflow in this region are well approximated by a lag-one normally distributed autoregressive process with $\rho=0.19$, and $C_{v}=0.25$. The index $r$ is one of the two parameters in a two-state Markov model of reservoir system states used for evaluating the conditional behavior of systems dominated by both within-year and over-year storage requirements, as shown by Vogel and Bolognese (1995) and Vogel et al. (1995). The resilience index is considered a better indicator (than $m$ ) of over-year and within-year behavior of a system, given the fact that it accounts for the serial correlation of inflows (Vogel and Bolognese 1995)

\subsection{Storage ratio}

The storage ratio $(S / \mu)$, where $S$ is the reservoir storage capacity has been used in the past to characterize system operations. Vogel et al. (1999) analyzed storage-yield curves for different regions across the United States and found that storage-yield curves may lead to different values depending on whether mean annual or monthly flows are used in the computation. Monthly flow based curves will generally show a higher value of storage ratio compared to annual based curves except when $C v \geq 0.3$ and $m<1$; when both annual and monthly flows based ratios provide similar (within $30 \%$ ) results of storage-yield curves. Though this indicator is less informative to system operations than other indicators (Vogel et al. 1999) it was included in order to compare this study with past reservoir system analyses.

\subsection{Reservoir system reliability}

For the design of hydraulic structures for flood control it is a standard practice to employ the average return period of a flood as the design event. Similarly, an index showing the average return period $N$ of a reservoir system shortage can be used for the design of a water supply system (Vogel 1987). The corresponding probability that a reservoir will deliver a constant yield $Y$, without failure, over $N$ years is known as no-failure reliability $R_{N}$ (Vogel et al. 1999). A failure for any given year is defined as the inability (shortage) of a water system to supply the anticipated annual demand (Vogel et al. 1999; Vogel and Bolognese 1995). For reservoirs fed by AR(1) normal and lognormal inflows, the storage capacity $S$ required to meet a constant yield $Y$ over $N$ years without failure follows a three-parameter lognormal distribution (Vogel 1985). Within-year systems fed by serially correlated normal and lognormal inflows can be accurately represented by a two-state Markov model (Vogel 1987; Vogel and Bolognese 1995; Vogel et al. 1995). Based on these assumptions the annual reliability $R_{a}$ (the steady-state probability, in a given year, that the reservoir system will deliver $Y$ without shortage) can be related to reliability $R_{N}$, resilience $r$ and $N$ using the following equation (Vogel et al. 1999)

$$
r=R_{a}\left[\frac{1-\left(\frac{R_{N}}{R_{a}}\right)^{1 /(N-1)}}{1-R_{a}}\right]
$$

For this study this equation was solved to estimate $R_{a}$ for $N=50$ and 100 years. As in Vogel et al. (1999) we assumed a no-failure reliability $R_{N}=0.5$. Although reservoirs in the system are interconnected, this assumption is reasonable since we considered the entire system as a unit. 


\subsection{Reservoir system vulnerability}

Reservoir system vulnerability $D$, which can be defined as the average magnitude of a water supply failure as a fraction of the annual yield (Y) (Vogel et al. 1999) is an additional indicator used to measure the level of stress of water resources in a region. This indicator was introduced as a socio-economic indicator by Vogel et al. (1999) and can be calculated from the storage-yield ratio as

$$
D=0.452\left(\frac{S}{Y}\right)^{1.27}
$$

where $S$ represents the active reservoir storage capacity. Examples in the literature estimated regional storage vulnerability assuming each reservoir was operated individually (Vogel et al. 1999). In this analysis we focus on all reservoirs operated conjunctively (Hardison 1972; Lof and Hardison 1966), guided by rules and constraints inherent in the present system operations.

\section{Data and modeling assumptions}

\subsection{Climate data}

Observed climate and streamflow data for this study include historical measurements of daily air temperature and precipitation covering a period from 1927 to 2004. These data used to drive the GWLF-VSA watershed model were obtained from up to nineteen stations for precipitation and four stations for temperature distributed throughout the WOH watershed region.

To create historical daily precipitation time series for each reservoir's watershed that could be input into the GWLF-VSA model, individual station precipitation values were spatially averaged using Thiessen polygon weighting (Burrough 1987). For air temperature inverse distance weighting was used and lapse rates were applied to account for variations in temperature with elevation (Zion et al. 2011).

Sixteen projections of future air temperature and precipitation (Table 2) were calculated using the European Centre Hamburg Model (ECHAM), Goddard Institute for Space Studies (GISS), and the National Center for Atmospheric Research (NCAR) GCM model simulations for three scenarios, and two future time periods or time slices.

Future climate projections were constructed using a delta change method (e.g. Hay et al. 2000; Gleick 1986) also known as change factor methodology (Anandhi et al. 2011). In delta change method monthly factors are calculated from the difference between GCM baseline and future simulated using pooled monthly data for the two time slices (Anandhi et al. 2011). The calculated delta change factors were then combined with records of observed data

Table 2 List of GCM, emission scenarios and time slices used to develop climate change scenarios for this study. 20C3M represent the baseline (from the 20th century experiment model runs)

\begin{tabular}{llll}
\hline GCM & $20 \mathrm{C} 3 \mathrm{M}$ & Emission scenario & Future time slices \\
\hline ECHAM & $1981-2000$ & A2, A1B, B1 & $2046-2065,2081-2100$ \\
GISS & $1981-2000$ & A2, A1B, B1 & $2046-2065,2081-2100$ \\
NCAR & $1980-1999$ & A2, A1B & $2046-2065,2080-2099$ \\
\hline
\end{tabular}


(additively for air temperature and multiplicatively for precipitation) to generate future climate projections for each scenario. In this manuscript we will refer to the 2046-2065 and 2081-2100 periods as the 2055s and 2090s, respectively. The baseline scenario represents model runs using the observed forcing data.

Projected changes in average monthly air temperature indicate consistent air temperature increases throughout the year with larger increases for the later time slice (Fig. 3). Precipitation is generally projected to increase in most months, but this increase is accompanied by much greater variability. These increases appear to be somewhat greater and more variable in the $2055 \mathrm{~s}$ time period.

\subsection{Modeling assumptions}

OASIS simulations were conducted for the entire NYCWSS, which includes the upper and lower Delaware, Catskill, and Croton subsystems (Fig. 1). However, only the WOH portion (the upper Delaware and Catskill basins) was simulated using both current and future modeled inflows. The remaining Croton (East of Hudson (EOH)) portion of NYCWSS and the lower Delaware (LD) were simulated using historical flow inputs for all baseline and future scenarios. Though these two portions have an impact on the water routing processes in $\mathrm{WOH}$, we choose to maintain this assumption for this analysis because $\mathrm{EOH}$ contributes about $10 \%$ of all NYCWSS requirements and the LD does not contribute any flow to NYC. NYC and OC average demand levels and system operation rules across the system were considered stationary and remained unchanged between baseline and future simulations.

\section{Evapotranspiration, snow and reservoir inflows in the study area}

Simulations with GWLF-VSA revealed increased growing season ET and decreased snowfall and snowpack as temperature increased (Fig. 4). Snowfall and snowpack are projected to

Future 2055s

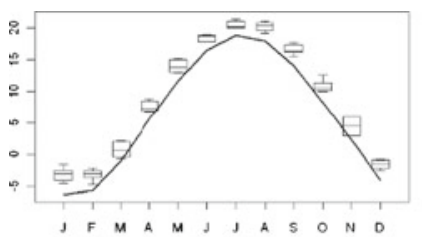

a) Air temperature $\left({ }^{\circ} \mathrm{C}\right)$

b) Precipitation (cm/day)

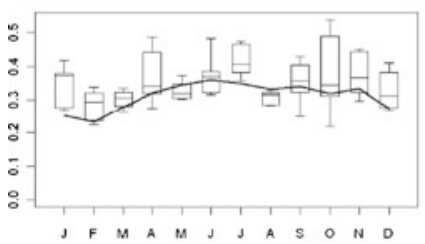

Future 2090s
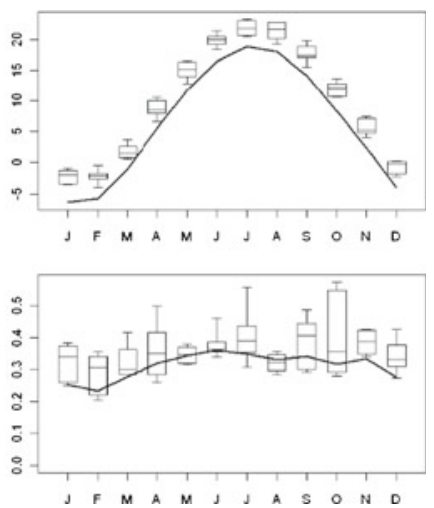

Fig. 3 Monthly average input precipitation and average daily air temperature for baseline and eight scenarios. Graphs are representative for the 2055s and 2090s future climate scenarios. Data consist of areal averages over all WOH watersheds. The solid lines on the graphs show the baseline scenario. The mid-way line in the boxes shows the median value of the monthly average for the climate scenarios, the extent of the boxes show the range of averages for the middle six scenarios, the whiskers show the range of all eight scenarios. Precipitation units are given in centimetres per day 
Future 2055s

a) Evapotranspiration (cm/day)

b) Snowfall (cm/day)

C) Snowpack (cm)
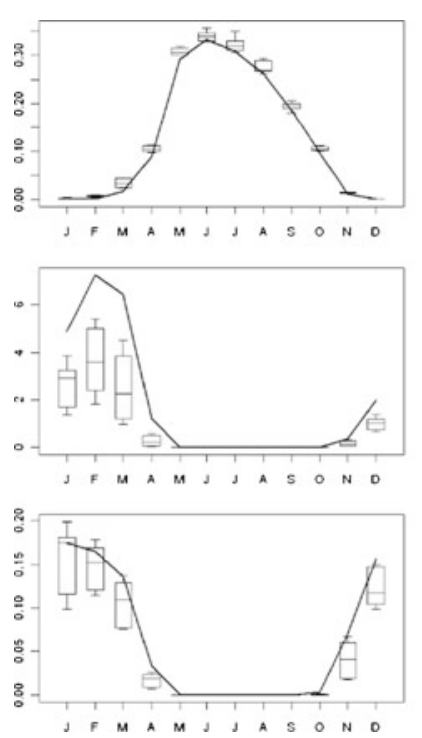

Future 2090s
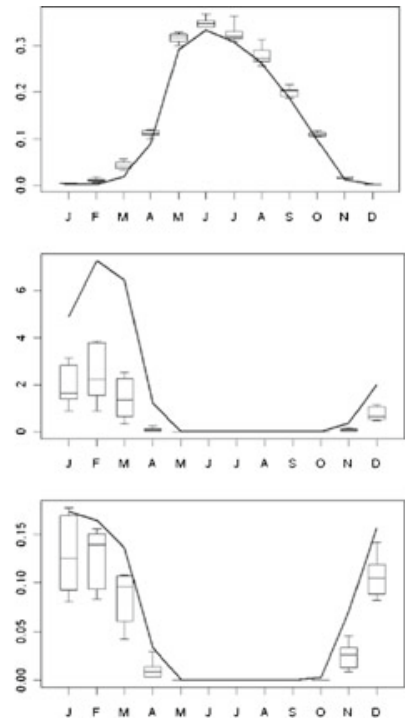

Fig. 4 Monthly mean evapotranspiration, snowfall and snowpack for baseline and future scenarios as areal averages for all WOH watersheds. The solid lines on the graphs show the baseline scenario. The mid-way line in the boxes shows the median value of the monthly average for the climate scenarios, the extent of the boxes show the range of averages for the middle six scenarios, the whiskers show the range of all eight scenarios. Boxplots represent simulated future 2055s and 2090s periods. The units are centimeters per day (cm/day) and centimeters $(\mathrm{cm})$

greatly decrease during the winter months, as increased temperature causes more of the precipitation to fall as rain and the snowpack that does develop to melt earlier in the year (Matonse et al. 2011).

Results from most future simulations show an increase in annual median inflow to Delaware and Caskill subsystems (Fig. 5). Though, the absolute magnitude is higher for

a) Annual Inflow for Delaware Subsystem

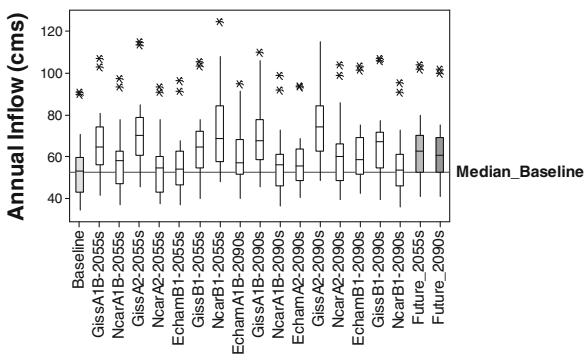

b) Annual Inflow for Catskill Subsystem

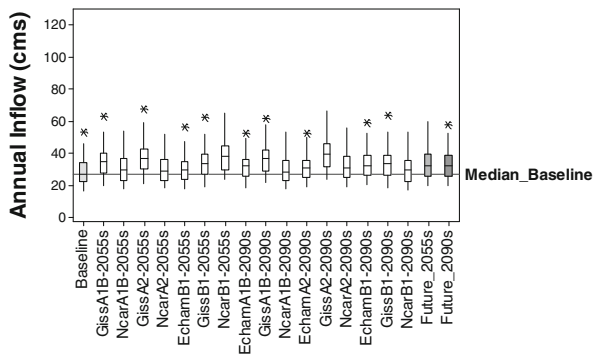

Fig. 5 Annual inflow for baseline (in light grey color) and for future GCMs climate simulations (white boxes). Medium dark gray boxes represent the combination of all future 2055s and dark gray all future 2090s simulations. The units are cubic meters per second (cms). For this and all subsequent figures box-plots show the bounds between the 25th (Q1) and 75th (Q3) quartiles, and the whiskers represent the lowest and highest data values within the lower $(\mathrm{Q} 1-1.5 *(\mathrm{Q} 3-\mathrm{Q} 1))$ and upper $(\mathrm{Q} 3+1.5 *(\mathrm{Q} 3-\mathrm{Q} 1)$ limits. The stars represent outliers. The dark horizontal lines in the box-plots represent the median. All statistics are calculated using a 20 year period 
the larger Delaware subsystem, variations in annual inflow simulated for future conditions are similar to baseline for both subsystems, as was expected given the dependence of the delta change method on historical data. Among the three GCMs the magnitudes of change are mixed but with GISS apparently exhibiting higher values, more often. For both subsystems, a test of significance comparing the two time slices at a type I error $\alpha=0.05$, revealed insufficient evidence to reject the null hypothesis $\left(\mathrm{H}_{\mathrm{o}}\right)$ that the mean inflows for the 2055s and 2090s are equal.

Monthly box-plots for the baseline (white), future 2055s (light gray) and future 2090s (dark gray) streamflow shown in Fig. 6 were created for baseline and future time periods using the combined monthly data from all GCM and emission scenarios. These show average flows to be higher during winter and early spring with the present day high flows of March and April shifting to earlier in the year and becoming more evenly distributed throughout the winter-spring period. Such changes in the seasonality of streamflow are consistent with the combined effects of a decrease in snow and an increase in precipitation falling as rain, as well as earlier snow melt associated with higher temperatures during winter and spring (Fig. 3 and Fig. 4, respectively). This results in more water being available earlier during winter and relatively less water being available during late spring, due to a loss of snowpack storage. Despite this, summer inflows do not decrease, but in fact increase slightly during June (Catskill subsystem) and July (Catskill and Delaware subsystems).

During the growing season, part of the increased precipitation is offset by increased ET, resulting in only a slight increase in the inflow to the reservoirs. It is interesting to note that even though there is little change in flow during the growing season period, the average unsaturated zone soil moisture (not shown here) decreases slightly during the spring months. This is because the soil has a limited storage, and the increased precipitation cannot increase the maximum soil moisture storage. The increased ET rate in the future climate simulations therefore tends to enhance the decline in soil moisture storage from its maximum value during inter-storm periods.

\section{Results for system indicators}

To describe the state of the water supply system and help assess performance a number of indicators were selected and evaluated in terms of their ability to capture and display system changes associated with projected future climate change.

a) Monthly Inflow Delaware Subsystem

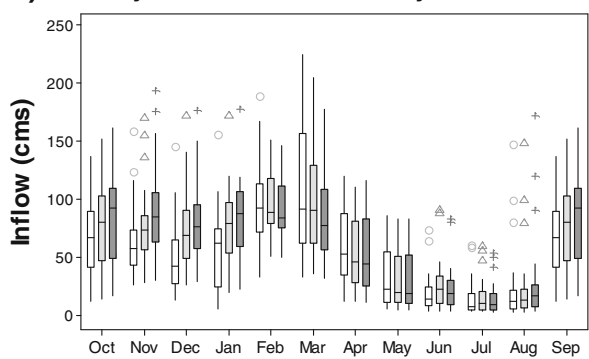

b) Monthly Inflow Catskill Subsystem

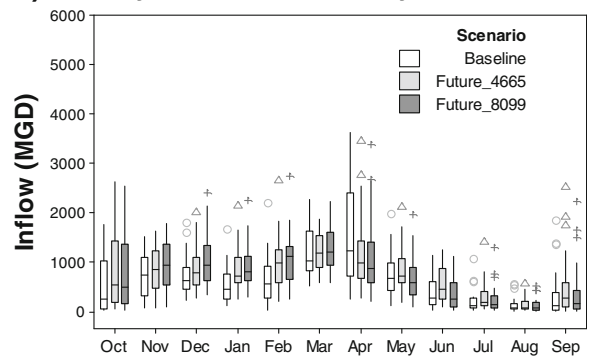

Fig. 6 Monthly inflow from baseline (white) and future simulated inflow for the 2055s (light gray) and 2090s (dark gray). Each box plot represents monthly variability derived from all 20 years for the specific time period. For future simulations that includes all combinations of GCMs and emission scenarios. Units are in cubic meters per second $(\mathrm{cms})$ 


\subsection{Reservoirs storage, spill and release}

Inflows for both Delaware and Catskill subsystems appear to peak in April under baseline conditions (white box-plots, Fig. 6a,b), while under future simulated climate inflows appear to peak earlier in winter and are more evenly distributed among the winter months due to more rainfall and earlier snowmelt. Slight increases in inflows during June and July and earlier increases in inflow during the September and October help slow drawdown through the summer and result in more rapid refill in the winter. These higher inflows are responsible for reservoirs becoming full earlier and for greater water storage during most of the year (Fig. 7a,b). The Catskill subsystem exhibits relatively higher storage throughout the entire summer, likely a result of generally higher inflows, and perhaps reflecting decreased diversions associated with turbidity events. Spill in both Delaware (Fig. 7c) and Catskill

a) Storage - Delaware Subsystem

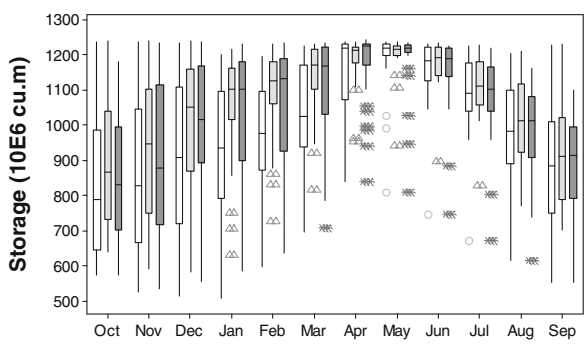

C) Spill - Delaware Subsystem

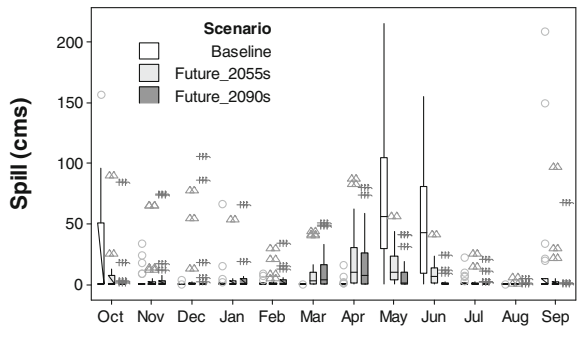

b) Storage - Catskill Subsystem

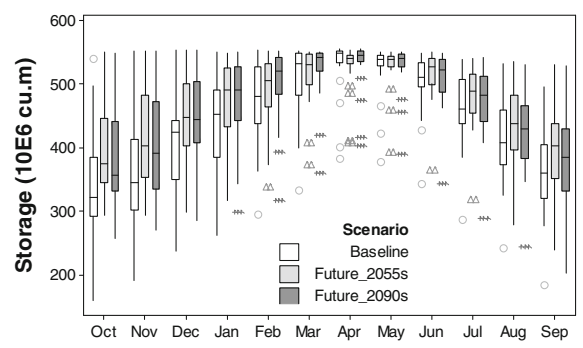

d) Spill - Catskill Subsystem

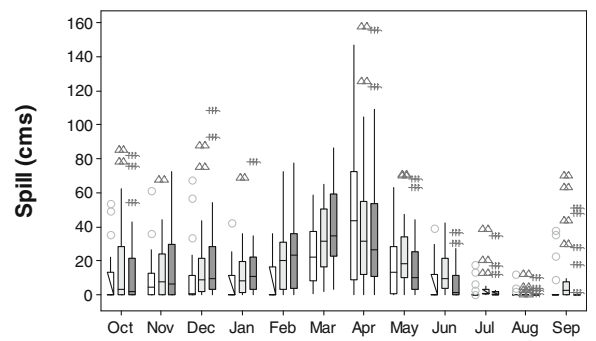

e) Release - Delaware Subsystem

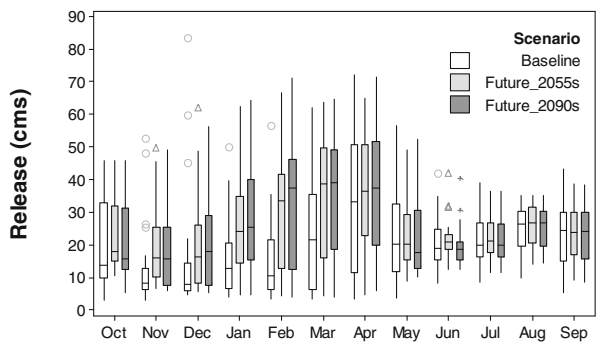

Fig. 7 Monthly storage, spill, and release patterns for Delaware and Catskill subsystems for the baseline (white), future 2055s (light gray) and future 2090s (dark gray) scenarios. Each box-plot represents monthly variability derived from all 20 years for the specific period. For future simulation that include all combinations of GCM models and emission scenarios. Units are in cubic meter $\left(10^{6} \mathrm{cu} . \mathrm{m}\right)$ and cubic meters per second (cms). The Catskill subsystem currently has no regulated releases 
(Fig. 7d) subsystems and releases in Delaware (Fig. 7e) subsystem appear to follow inflow patterns, with future increases predicted for the winter-spring period. Releases in the Delaware subsystem are driven by rules that include habitat protection and flood mitigation. There are currently no regulated releases from the Catskill subsystem.

While differences in storage among the two projected future climate time periods are minimal, changes in spill and release appear more pronounced for the end of the century. It is important to note that, although the total volume of simulated future releases and spills during late fall and winter increase somewhat, the volumes of spill and release never reach the highest levels encountered in the baseline period during April.

\subsection{Drought conditions occurrence}

Results from most future simulations show a decrease in average number of days under watch, warning and emergency drought conditions in both the Catskill and Delaware subsystems (Fig. 8). Changes in inflow patterns, including an increase in total flow and the lower streamflow percentiles, contribute to these results. However, when comparing the results from individual projected simulations in Fig. 8 it becomes apparent that the results show large variability. Of all model simulations used in this study NCAR_A1B-4665 appears to be the only one projecting an increase in number of days under emergency for the Delaware subsystem. In terms of number of days under warning and watch drought conditions most scenarios indicate a decrease for both subsystems but again, with high variability in the size of the reduction.

\subsection{Reservoir system performance}

\subsubsection{Demand ratio $\alpha$, standardized net inflow, coefficient of variation and storage ratio}

Results of standardized net inflow $(m)$ (Fig. 9) indicate an increase under future climate simulations. All $m$ values are above 1 (on average $>1.65$ ) indicating a continuing within-year behavior of the system. The interquantile range appears to be slightly higher for the $2055 \mathrm{~s}$ period and a few scenario simulations in the box-plot for the 2090s show $m$ values that are lower than the baseline scenario. As a consequence of the delta-change method, the coefficient of variation for baseline and future simulations are similar.

a) Delaware Subsystem

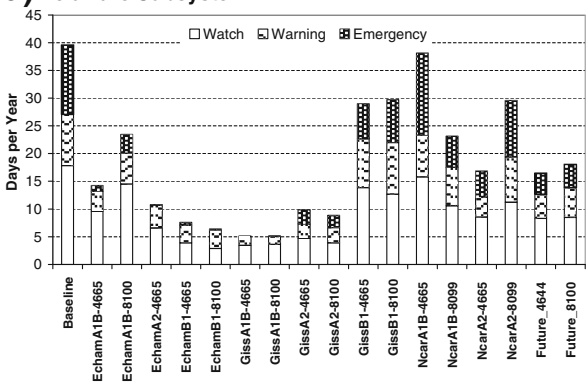

b) Catskill Subsystem

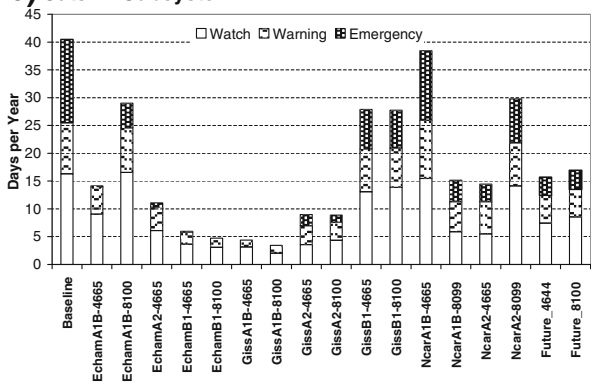

Fig. 8 Average number of days per year when the Delaware and Catskill subsystems are under emergency, warning, and watch drought conditions. The $\mathrm{x}$-axis represents the different climate simulation scenarios. On each graph the bars to the left represent the baseline scenarios, the two bars on the right represent an average over all future $2055 \mathrm{~s}$ and 2090 s simulations, respectively 

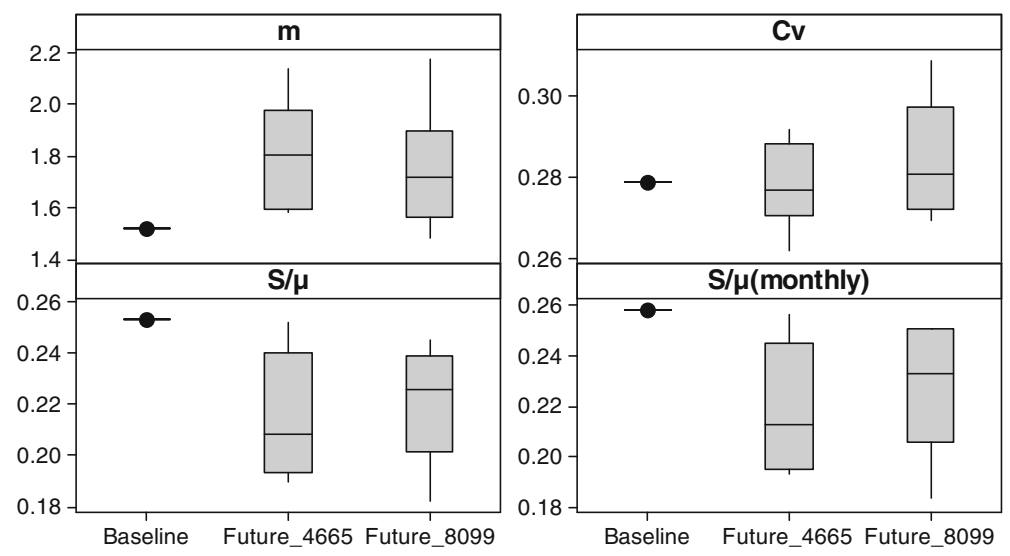

Fig. 9 Box-plots indicating standardized net flow $(m)$, coefficient of variation of annual flow $\left(C_{v}\right)$ and storage ratio using annual $(S / \mu)$ and monthly flow data $\left(S / \mu_{\text {(monthly) }}\right)$. Box-plots for the simulated future $2055 \mathrm{~s}$ and 2090s were developed using average values by each of the climate change scenario simulations for the WOH system. Baseline values are shown with dots

The coefficient of variation of annual inflow $\left(\mathrm{C}_{\mathrm{v}}\right)$ remains below 0.3 for most future simulations except for a few in the 2090s, while the storage ratio shows a decrease under future simulated climate. These results are consistent with findings by Vogel et al. (1999) who found that systems showing pronounced within-year behavior are associated with $\mathrm{C}_{\mathrm{v}}<1$ and $\mathrm{C}_{\mathrm{v}} \leq m \leq\left(1 / \mathrm{C}_{\mathrm{v}}\right)$. Also, Vogel et al. (1999) showed how for systems with $\mathrm{C}_{\mathrm{v}}$ less than 0.3 , the storage ratio based on annual flow differs from the storage ratio based on monthly inflows. Our results are consistent with those from Vogel et al. (1999) indicating slightly higher storage ratios when using monthly flows rather than annual flows; a sign of the impact of seasonality associated with monthly flows. Project changes in the coefficient of variation and storage ratios are within the range found by Vogel et al. (1999) for this region, while standardized net flow values are slightly higher, probably due to the fact that their estimations of yield and mean annual inflow were made at a larger regional scale.

\subsubsection{System resilience, reliability and vulnerability}

The impact of increased inflows is also reflected in Fig. 10 where future simulations indicate a more resilient reservoir system or a higher probability for the system to recover from a failure after one has occurred. Here again there is variability between calculations based on different future climate scenarios with a few simulations in both time slices showing a resilience lower than under baseline conditions.

Annual reliability of reservoirs across the United States is generally between 0.97 and 0.985 (Vogel et al. 1999), with annual reliability being the steady-state probability that a reservoir will deliver the required yield for a particular year without failure. Our baseline simulation (Fig. 10) suggests that WOH reservoirs are in the upper limit of this range and that future changes in climate will result in no substantial difference in annual reliability. The variability among the different model scenario simulations is less than 0.0015. A high positive correlation between resilience and reliability for the NYC reservoir system is not surprising; Vogel et al. (1999) arrived at similar results for reservoir systems in the eastern United States.

As under the present conditions projected $D$ for future climate simulations indicate that the $\mathrm{NYC}$ reservoir system will continue showing high resilience and low vulnerability $(D \approx 0.1)$. As 

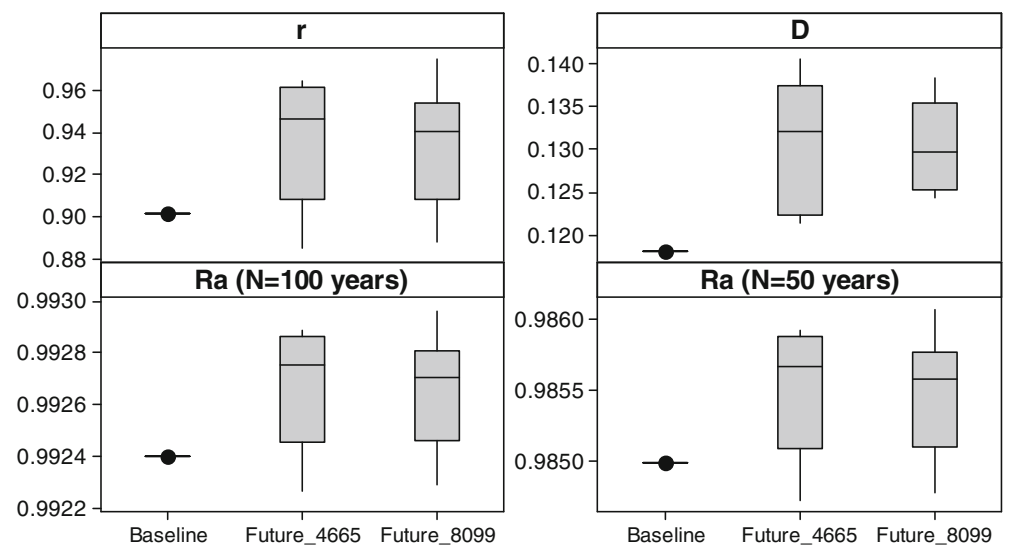

Fig. 10 Box-plots representative for system resilience $(r)$, annual reliability $(R a)$, and reservoir vulnerability $(D)$ for the WOH system. (N) represents the non-failure planning period for (Ra) calculation. The box-plots represent the simulated models average values for the future $2055 \mathrm{~s}$ and $2090 \mathrm{~s}$

$D$ is an indicator of average number of consecutive years a reservoir system fails to deliver an expected yield a unity vulnerability $(D=1)$ can be interpreted as a failure state that will last one year on average (Vogel et al. 1999). This is important because based on our results any eventual failure in the NYC reservoir system will last for far less than a year. Our $D, r$, and $R_{a}$ values are within the range found in previous studies for this region (e.g., Lane et al. 1999; Vogel et al. 1999).

\section{Summary and conclusions}

This study focuses on the potential impacts of climate change on NYC water supply with regards to reservoir operations and water supply system performance. An ensemble of three GCMs, three emission scenarios and two future time periods were used to simulate a present baseline and 16 different future climate change projections for the west of Hudson (WOH) region of the NYCWSS, which contributes more than $90 \%$ of all water needed to meet NYC water demands. Air temperature and precipitation derived from these scenarios were used as inputs to the GWLF watershed model to simulate inflows required to run OASIS and simulate reservoir operations.

Results from this study comparing baseline inflow estimations with simulations for two future time slices representing the $2055 \mathrm{~s}$ and 2090s suggest that the trend of increasing streamflow identified in historical records from Catskill basins (Burns et al. 2007) will continue so that on average annual streamflow will increase by approximately $97 \mathrm{~mm}$ in the next fifty year period. No statistically significant difference was detected in the annual streamflow between the future 2055s and 2090s.

On a seasonal basis monthly inflows will rise for almost all months with the greatest changes during winter and early spring due to a combined effect of more rainfall and snowmelt associated with higher temperatures (Matonse et al. 2011). Increases in winter inflows are more pronounced during the 2090s compared to 2055s. During summer projected changes in streamflow are relatively small suggesting that increased evapotranspiration (ET) rates associated with higher summer temperatures largely counteracts increased precipitation at this time. This result is not surprising; in the past Burns et al. (2007) and 
Blake et al. (2000) suggested that higher ET rates will impact inflows in a warmer climate. Future summer flows remained basically unchanged as both ET and precipitation increased; effectively canceling the individual effects of each component. It should be noted that the uncertainty of future precipitation is much greater than that of future temperature. If the future precipitation estimates are over-predictions, then summer low flows could decrease more dramatically and annual inflow into the reservoir system will be less than expected.

To better gauge the impact of climate change on reservoir system operation, indicators such as reservoir inflow, storage, release, spill, and drought level were examined. Other indicators, such as the coefficient of variation of inflow, standardized net inflow, reservoir system resilience, reliability and vulnerability which have been used in the literature to measure and compare reservoir system performance were also examined.

Based on our results the combined effects of earlier snowmelt, higher rainfall and higher ET rates projected to occur during the two simulated future time slices will lead to:

1. Reservoirs filling earlier with inflows more evenly distributed during winter and early spring and a reduction in the historically observed April runoff peak. Under these conditions releases and spills will become higher during late fall and winter and less during April.

2. A decrease in the average number of days the Catskill and Delaware reservoirs will be under drought emergency, warning and watch conditions.

3. An increase in average standardized net inflow $m(m>1)$. Average coefficients of variation $C_{v}$ for future simulations that are similar to baseline and less than 0.3 , and decreased average storage ratios $(D<1)$, but with storage ratios based on monthly flows being slightly higher than storage ratios based on annual flows, indicating the effect of seasonality present in monthly flows. Our results support a previous regional analysis that characterizes reservoirs systems for the eastern United States region by $C_{v}<1$ and $C_{v} \leq m \leq\left(1 / C_{v}\right)$ and are consistent with a reservoir system dominated by within-year variability; also found in previous studies to be characteristic for the eastern United States region.

Historical meteorology and model simulated baseline and future meteorology and streamflow were used in this study of the effects of climate change on NYC water supply. For this study only historical water demands and operational rules were available and these were considered stationary during future simulations. Maintaining current rules and demands helps evaluate the system effectiveness in responding to changes in climate alone (Matonse et al. 2011). However, population and other socio economic changes in the future may alter the current level of water demand (IPCC 2001). In addition historical data analysis indicates a positive correlation between water demands and high temperatures suggesting a potential direct impact of climate change on demands. These factors and any changes in regulatory flow requirements and water quality standards may have an impact on system operations and need to be accounted for in future studies. Also, the variability of inflows associated with future climate simulations are not directly obtained from the GCMs variability, but reflect the variability of the historic climate, a limitation of the delta change method. As water supply systems are sensitive to the frequency and magnitude of extreme hydrological events the use of model ensembles including other (dynamical and/or statistical) downscaling methods can potentially provide additional information that is important for the impact assessment and adaptation processes (Stainforth et al. 2007).

In conclusion, according to the climate models and scenarios applied in this study the NYC reservoir system will most likely continue to show high resilience, high annual reliability and relatively low vulnerability. As in previous studies reliability and resilience show a positive correlation. These conclusions will continue to be evaluated as updated climate model scenarios and future demand projections become available. 
Acknowledgements The authors are grateful to New York City Department of Environmental Protection (NYC DEP) who provided funding for the research that led to this manuscript. This paper does not necessarily reflect the official views of NYC DEP, and no endorsement should be inferred; to Grantley W Pike for the valuable review; and to David Lounsbury and Donald Kent of the NYC DEP water quality modeling group for their inputs. Also, the authors want to thank the Columbia University Center for Climate Systems Research and the NASA Goddard Institute for Space Studies for providing the NCAR, GISS and ECHAM GCM data.

Open Access This article is distributed under the terms of the Creative Commons Attribution License which permits any use, distribution, and reproduction in any medium, provided the original author(s) and the source are credited.

\section{References}

Anandhi A, Frei A, Pierson DC, Schneiderman EM, Zion MS, Lounsbury D, Matonse A (2011) Examination of change factor methodologies for climate change impact assessment. Water Resour Res 47:W03501. doi:10.1029/2010WR009104

Bates B, Kundzewicz C, Wu W, Palutikof P (eds) (2008) Climate change and water. Technical Paper of the Intergovernmental Panel on Climate Change. Geneva, Switzerland, IPCC Secretariat, p 210

Beven KJ, Kirkby MJ (1979) A physically-based, variable contributing area model of basin hydrology. Hydrolog Sci Bull 24:43-69

Black AR, Rowan JS, Duck RW, Bragg OM, Clelland BE (2005) DHRAM: a method for classifying river flow regime alterations for the EC water framework directive. Aquatic Conservation 15:427-446

Blake R, Khanbilvardi R, Rosenzweig C (2000) Climate change impacts on the New York City's water supply system. J Am Water Resour Assoc 36:279-292

Brekke LD, Maurer EP, Anderson JD, Dettinger MD, Townsley ES, Harrison A, Pruitt T (2009) Assessing reservoir operations risk under climate change. Water Resour Res 45:W04411. doi:10.1029/ 2008WR006941

Burns DA, Klaus J, McHale MR (2007) Recent climate trends and implications for water resources in the Catskill Mountain region, New York, USA. J Hydrol 336:155-170. doi:10.1016/j.jhydrol.2006.12.019

Burrough PA (1987) Principles of geographical information systems for land resources assessment. Clarendon, Oxford, 186

Chang LC, Chang FJ (2001) Intelligent control of modeling of real-time reservoir operation. Hydrol Process 15:1621-1634. doi:10.1002/hyp.226

Cole TT, Wells SA (2002) CE-QUAL-W2: a two-dimensional, laterally averaged, hydrodynamic and water quality model, version 3.1. Instruction Report EL-2002-1., U.S. Army Engineering and Research Development Center, Vicksburg, MS

Frei A, Armstrong RL, Clark MP, Serreze MC (2002) Catskill mountain water resources vulnerability, hydroclimatology, and climate-change sensitivity. Ann Assoc Am Geogr 92(2):203-224

Gao Y, Vogel RM, Kroll CN, Poff NL, Olden JD (2009) Development of representative indicators of hydrologic alteration. J Hydrol 374:136-147. doi:10.1016/j.jhydrol.2009.06.009

Gleckler PJ, Taylor KE, Doutriaux C (2008) Performance metrics for climate models. Water Resour Res 113: D06104. doi:10.1029/2007JD008972

Gleick PH (1986) Methods for evaluating the regional hydrologic effects of global climate changes. J Hydrol 88:97-116

Haith DA, Shoemaker LL (1987) Generalized watershed loading functions for stream flow nutrients. Water Resour Bull 23(3):471-478

Harberg RJ (1997) Planning and managing reliable urban water systems. American Water Works Association, Denver

Hardison CH (1972) Potential United States water-supply development. J Irrig Drain Div ASCE 98(3):479492

Hay LE, Wilby RL, Leavesley GH (2000) A comparison of delta change and downscaled GCM scenarios for three mountainous basins in the United States. J Am Water Resour Assoc 36(2)

Hashimoto T, Stedinger JR, Loucks DP (1982) Reliability, resiliency, and vulnerability criteria for water resources system performance evaluation. Water Resour Res 18:14-20

HydroLogics Inc (2007) User manual for OASIS with OCL, Columbia, MD

Hunt A, Watkiss P (2011) Climate change impacts and adaptation in cities: a review of the literature. Clim Chang 104:13-49. doi:10.1007/s10584-010-9975-6 
IPCC (2001) Climate Change 2001: the scientific basis. In: Houghton JT, Ding Y, Griggs DJ, Noguer M, van der Linden PJ, Dai X, Marskell K, Johnson CA (eds) Contribution of working group I to the third assessment report of the intergovernmental panel on climate change. Cambridge University Press, p 881

Joint Editorial Board Representing APHA, ASCE, AWWA, and WPCF (1969) Glossary: Water and Wastewater Control Engineering

Lane ME, Kirshen PH, Vogel RM (1999) Indicators of impacts of global climate change on U.S. water resources. J Water Resour Plan Manag, ASCE 125(4):194-204

Lof GOG, Hardison CH (1966) Storage requirements for water in the United States. Water Resour Res 2 (3):323-354

Mays LW, Tung Y-K (1992) Hydrosystems engineering and management. McGraw-Hill Inc, New York

Mayer RA (1993) Safe yield study of the New York City reservoir system. Progress report: Catskill/Delaware filtration. Strategic Services Division, NYC DEP

Milly PCD, Dunne KA, Vecchia AV (2005) Global pattern of trends in streamflow and water availability in a changing climate. Nature 438:347-350. doi:10.1038/nature04312

Matonse AH, Pierson DC, Frei A, Zion MS, Schneiderman EM, Anandhi A, Mukundan R, Pradhanang SM (2011) Effects of changes in snow pattern and the timing of runoff on NYC water supply system. Hydrol Process 25:3278-3288. doi:10.1002/hyp.8121

Neitsch SL, Arnold JG, Kiniry JR, Srinivasan R, Williams JR (2005) Soil and water assessment tool: theoretical documentation, version 2005. Agricultural Research Service, Temple, 476

New York City Department of Environmental Protection (NYCDEP) (2011) 2011 Watershed protection program summary and assessment. March 2011. http://www.nyc.gov/html/dep/pdf/reports/ fad51_wmp_2011_fad_assessment_report_03-11.pdf. Accessed 27 April 2012

New York City Department of Environmental Protection (NYCDEP) (2008) Climate change program: assessment and action plan. May 2008. Report 1. A Report based on the ongoing work of the DEP climate change task force. http://www.nyc.gov/html/dep/pdf/climate/climate_complete.pdf. Accessed 27 April 2012

Perrens SJ, Howell DT (1972) Effects of serially correlated inflows on reservoir behavior. Water Resour Res 8:642-647

Priestley CHB, Taylor RJ (1972) On the assessment of surface heat flux and evaporation using large-scale parameters. Mon Weather Rev 100:81-92

Richter BD, Baumgartner JV, Powell J, Braun DP (1996) A method for assessing hydrologic alteration within ecosystems. Conserv Biol 10:1163-1174

Rogers PR (1999) Environmental indicators, Journal of Water Resources Planning and Management. ASCE $125(2): 74-75$

Rosenzweig C, Solecki WD (2001) Climate change and a global city: learning from New York. Environment 43(3):8-18

Schneiderman EM, Steenhuis TS, Thongs DJ, Easton ZM, Zion MS, Neal AL, Mendoza GF, Walter MT (2007) Incorporating variable source area hydrology into the curve number based Generalized Watershed Loading Function model. Hydrol Process 21:3420-3430

Schneiderman EM, Pierson DC, Lounsbury DG, Zion MS (2002) Modeling the Hydrochemistry of the Cannonsville Watershed with Generalized Watershed Loading Functions (GWLF). J Am Water Resour Assoc 38(5):1323-1347

Seager R et al (2007) Model projections of an imminent transition to a more arid climate in southwestern North America. Science 316:1181-1184. doi:10.1126/Science.1139601

Stainforth DA, Downing TE, Washington R, Lopez A, New M (2007) Issues in the interpretation of climate model ensembles to inform decisions. Phil Trans R Soc 365:2163-2177. doi:10.1098/rsta.2007.2073

Vicuna S, Dracup JA (2007) The evolution of climate change impact studies on hydrology and water resources in California. Clim Chang 82:327-350. doi:10.1007/s10584-006-9207-2

Vogel RM (1985) The variability of reservoir storage estimates, Ph.D. thesis, Cornell University, Ithaca, NY

Vogel RM (1987) Reliability indices for water supply systems, ASCE. J Water Resour Plan Manag Division 113(4):563-579

Vogel RM, Fennessey NM, Bolognese RA (1995) Storage-reliability-resilience-yield relations for Northeastern United States, ASCE. J Water Resour Plan Manag Division 121(5):365-374

Vogel RM, Sieber J, Archfield SA, Smith MP, Apse CD, Huber-Lee A (2007) Relations among storage, yield and instream flow. Water Resour Res 43. doi:10.1029/2006WR005226

Vogel RM, Lane M, Ravindiran RS, Kirshen P (1999) Storage reservoir in the United States, Journal of Water Resources Planning and Management. ASCE 125(5):245-254

Vogel RM, Bolognese RA (1995) Storage-reliability-resilience-yield relations for over-year water supply systems. Water Resour Res, 31(3):645-654

Vogel RM, Stedinger JR (1987) Generalized storage reliability yield relationships. J Hydrol 89:303-327 
Walter MT, Mehta VK, Marrone AM, Boll J, Gerard-Merchant P, Steenhuis TS, Walter MF (2003) A simple estimation of the prevalence of Hortonian flow in New York City's watersheds. ASCE J Hydrolog Eng 8 (4):214-218

Yin X, Yang Z, Yang W, Zhao Y, Chen H (2010) Optimized reservoir operation to balance human and riverine ecosystem needs: model development, and a case study for the Tanghe reservoir, Tang river basin, China. Hydrol Process 24:461-471. doi:10.1002/hyp.7498

Zion MS, Pradhanang SM, Pierson DC, Anandhi A, Lounsbury DG, Matonse AH, Schneiderman EM (2011) Investigation and modeling os winter streamflow timing and magnitude under changing climate conditions for the Catskill Mountain region, New York, USA. Hydrol Process 25:3289-3301. doi:10.1002/hyp.8174 